\title{
Analysis of the New Prescriptions Created in Our Organization during the First Twelve Months after the Declaration of the State of Alarm Due to SARS-CoV-2
}

\author{
Mendizabal Olaizola A and Valverde Bilbao E* \\ Primary Care Pharmacist, Bidasoa Hospital, Hondarribia, Bidasoa Integrated Healthcare Organisation (IHO), Osakidetza, Spain
}

${ }^{\star}$ Corresponding author: Valverde Bilbao E, Primary Care Pharmacist, Bidasoa Hospital, Hondarribia, Bidasoa Integrated Healthcare Organisation (IHO), Osakidetza, Spain

Received: June 18, 2021; Accepted: June 25, 2021; Published: June 25, 2021

\section{Commentary}

One year after the declaration of the state of alarm due to SARSCoV-2 in Spain (March 14, 2020) the authors wanted to know the impact that the changes implemented in the health system have had on the creation of new prescriptions in our organization (Integrated Health Organization (IHO) Bidasoa). Bidasoa IHO is a health organization belonging to Osakidetza, it serves more than 85,000 inhabitants and is composed of 3 health centers and a regional hospital.

This is the continuation of the analysis made of the first 3 months after the declaration of the state of alarm [1] and analyzes the new prescriptions made from March 14, 2020 to March 13, 2021 (one year since the declaration of the first state of alarm due to the pandemic in Spain) and compares them with those started between March 14, 2019 and March 13, 2020 (one year earlier). The prescriptions created by Primary Care physicians (family doctors, pediatricians, and doctors of Continuing Care Points and nursing homes), hospital outpatient clinics and outpatient consultations, and the hospital emergency services have been reviewed. All the data were obtained from the OAS (Oracle Analytics Server) tool, which records the electronic prescriptions [2].

In the Bidasoa IHO during this period 231,876 new prescriptions were created compared to 171,830 a year earlier, which represents a reduction of $25.9 \%$ (Table 1 ).

During the first twelve months after the declaration of the state of alarm, there have been substantial changes in the way of working in health care, including an increase in telephone consultations and a decrease in face-to-face consultations, or the successive automatic

Table 1: Prescriptions initiated between March 14, 2020 and March 13, 2021 in Bidasoa IHO, compared to the same period of the previous year [2]

\begin{tabular}{|l|c|c|c|}
\hline New prescriptions & $\mathbf{2 0 1 9 / 2 0 2 0}$ & $\mathbf{2 0 2 0 / 2 0 2 1}$ & Variation \\
\hline Total & 231.876 & 171.830 & $-25,9 \%$ \\
\hline Acute & 94.837 & 69.318 & $-26,9 \%$ \\
\hline Chronic & 137.039 & 102.512 & $-25,2 \%$ \\
\hline On demand & 168.076 & 117.909 & $-29,8 \%$ \\
\hline Gender: Men & 41.033 & 35.529 & $-13,4 \%$ \\
\hline \multicolumn{1}{|c|}{ Women } & 22.767 & 18.392 & $-19,2 \%$ \\
\hline
\end{tabular}

extensions of many of the chronic and on demand treatments. These facts are emerging as the most plausible reasons for the decrease in the new prescriptions initiated in this period.

The total number of medication containers dispensed in pharmacy offices between March 2020 and February 2021 compared to the same period of the previous year, has been reduced by $3 \%$ [3]. In other words that means that, in the same period in which there was a $25.9 \%$ reduction in the creation of new prescriptions, only $3 \%$ less medication was dispensed in pharmacies. This difference could be explained, among other reasons, by the successive automatic extensions of the treatments that have been carried out in the last year, which could mean that fewer treatment reviews have been carried out for chronic patients.

New prescriptions were analyzed by therapeutic groups and 3 groups stand out in terms of their reduction: in group $\mathrm{R}$ (respiratory) new prescriptions were reduced by $42.9 \%$, in group M (musculoskeletal) by $35.4 \%$ and in group J (anti-infectives for systemic use) by $34.6 \%$ (Figure 1).

Likewise, some therapeutic subgroups have been reviewed and it is observed that in the vast majority of subgroups there is a reduction in the initiation of new prescriptions. The reduction is greater than $30 \%$ compared to the previous year in some subgroups such as: agents affecting bone structure and mineralization (M05) 41.9\%, agents against obstructive airways conditions (R03) $39.4 \%$, systemic

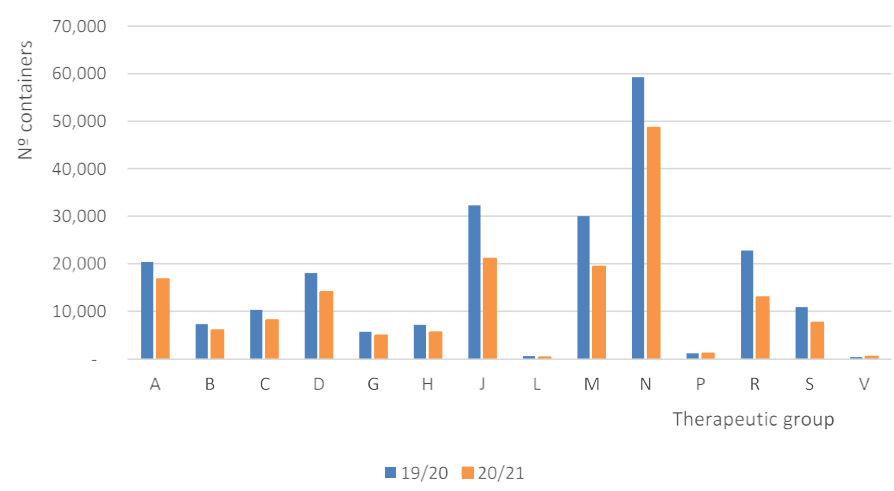

Figure 1: Start of prescriptions by therapeutic group March 14, 2020 to March 13, 2021 vs. same period of the previous year [2] 
Valverde Bilbao E (2020) Analysis of the New Prescriptions Created in Our Organization during the First Twelve Months after the Declaration of the State of Alarm Due to SARS-CoV-2

antibiotics (J01) 36.4\%, opioids (N02A) 36.3\%, NSAIDs (M01A) $35.9 \%$, other analgesics and antipyretics (N02B) 31.6\%, otologicals (S02) $31.1 \%$, lipid modifiers (C10) $30.9 \%$ and calcium channel blockers (C08) $30 \%$. On the contrary, an increase in the creation of new prescriptions was detected in the following subgroups: insulins (A10A) $52.9 \%$, diuretics (C03) $1.4 \%$ and direct-acting anticoagulants (B01AE and B01AF) 10.5\% (Table 2).

In some of the therapeutic subgroups, we found it interesting to go down to the level of active ingredients. In the NSAID group, there have been significant decreases in the initiation of new prescriptions in all the most prescribed active ingredients, highlighting ibuprofen (Table 3).

Systemic antibiotics have also suffered a significant decrease in the number of prescriptions created during the year that followed the declaration of the state of alarm, with several active ingredients with a reduction of around or more than $60 \%$ reduction compared to the

Table 2: Variation in the initiation of prescriptions in some therapeutic groups under the study period [2].

\begin{tabular}{|c|c|c|c|}
\hline Therapeutic subgroup & 2019 & 2020 & Variation \\
\hline A02. Antacids & 8.664 & 6.931 & $-20,0 \%$ \\
\hline A10A. Insulins & 408 & 624 & $52,9 \%$ \\
\hline A10B. Non-insulin antidiabetics & 1.439 & 1.053 & $-26,8 \%$ \\
\hline A11. Vitamins & 2.105 & 1.611 & $-23,5 \%$ \\
\hline B01. Antithrombotics & 3.577 & 3.103 & $-13,2 \%$ \\
\hline B01AE and B01AF. Direct-acting anticoagulants & 218 & 241 & $10,5 \%$ \\
\hline B03. Antianemics & 3.370 & 2.752 & $-18,3 \%$ \\
\hline C02. Antihypertensives & 126 & 102 & $-19,0 \%$ \\
\hline C03. Diuretics & 1.776 & 1.801 & $1,4 \%$ \\
\hline C07. Beta-blockers & 885 & 799 & $-9,7 \%$ \\
\hline C08. Calcium channel blockers & 874 & 612 & $-30,0 \%$ \\
\hline C09. Inhibitors of the renin-angiotensin system & 3.490 & 2.573 & $-26,3 \%$ \\
\hline C10. Lipid modifiers & 1.631 & 1.127 & $-30,9 \%$ \\
\hline J01. Systemic antibiotics & 30.599 & 19.469 & $-36,4 \%$ \\
\hline M01A. Nonsteroidal anti-inflammatory drugs & 28.591 & 18.327 & $-35,9 \%$ \\
\hline M05. Agents for bone structure and mineralization & 363 & 211 & $-41,9 \%$ \\
\hline N02A. Opioids & 9.634 & 6.135 & $36,3 \%$ \\
\hline N02B. Other analgesics and antipyretics & 24.128 & 18.487 & $-23,4 \%$ \\
\hline N02C. Anti-migraine & 472 & 323 & $-31,6 \%$ \\
\hline N03. Antiepileptics & 2.547 & 2.329 & $-8,6 \%$ \\
\hline N04. Antiparkinsonians & 159 & 116 & $-27,0 \%$ \\
\hline N05. Antipsychotics & 13.840 & 13.319 & $-3,8 \%$ \\
\hline N05B and N05C. Benzodiazepines & 11.010 & 10.463 & $-5,0 \%$ \\
\hline N06A. Antidepressants & 4.879 & 4.529 & $-7,2 \%$ \\
\hline R03. Agents for obstructive airway conditions respiratorias & 7.600 & 4.595 & $-39,5 \%$ \\
\hline R06A. Systemic antihistamines & 6.380 & 4.535 & $-28,9 \%$ \\
\hline S01. Ophthalmology & 8.101 & 5.764 & $-28,8 \%$ \\
\hline S02. Otologic & 2.464 & 1.698 & $-31,1 \%$ \\
\hline
\end{tabular}

previous year (amoxicillin, azithromycin, phenoxymethylpenicillin, levofloxacin or moxifloxacin). Cefuroxime and, to a lesser degree, fosfomycin, have increased the new prescriptions in this period (Table 4).

The profile of new antibiotic prescriptions in pediatrics was also analyzed (Table 5). The reduction in new antibiotic prescriptions in pediatrics is even more pronounced than in the case of adults, and has remained so during these 12 months.

Finally, we wanted to check whether the significant decrease in new NSAID prescriptions could have shifted to other analgesics, such as paracetamol or metamizole. This was not the case in the periods analyzed previously and does not appear to be the case at present (Table 6).

Table 3: Active ingredients of the group of NSAID with the highest number of starts of prescriptions in the study period [2].

\begin{tabular}{|l|c|c|c|}
\hline Non-steroidal anti-inflammatory drugs & $\mathbf{2 0 1 9 / 2 0}$ & $\mathbf{2 0 2 0 / 2 1}$ & Variation \\
\hline Celecoxib & 632 & 538 & $-14,9 \%$ \\
\hline Dexketoprofen & 4.050 & 3.183 & $-21,4 \%$ \\
\hline Diclofenac (including associations) & 2.695 & 1.786 & $-33,7 \%$ \\
\hline Etoricoxib & 1.133 & 891 & $-21,4 \%$ \\
\hline Ibuprofen (including ibuprofeno arginine) & 15.102 & 8.341 & $-44,8 \%$ \\
\hline Naproxen (including association with esomeprazole) & 4.364 & 3.238 & $-25,8 \%$ \\
\hline
\end{tabular}

Table 4: Active ingredients of the group of systemic antibiotics with the highest number of prescription starts in the period under study [2].

\begin{tabular}{|l|c|c|c|}
\hline Systemic antibiotics & $\mathbf{2 0 1 9 / 2 0}$ & $\mathbf{2 0 2 0 / 2 1}$ & Variation \\
\hline Amoxicillin & 7.905 & 3.154 & $-60,1 \%$ \\
\hline Amoxicillin/clavulanate & 7.558 & 5.074 & $-32,9 \%$ \\
\hline Azithromycin & 4.268 & 1.786 & $-58,1 \%$ \\
\hline Cefuroxime & 1.245 & 1.515 & $21,7 \%$ \\
\hline Ciprofloxacin & 1.519 & 1.392 & $-8,4 \%$ \\
\hline Clarithromycin & 355 & 221 & $-37,7 \%$ \\
\hline Phenoxymethylpenicillin & 165 & 56 & $-66,1 \%$ \\
\hline Fosfomycin & 3.831 & 3.873 & $1,1 \%$ \\
\hline Levofloxacin & 1.560 & 614 & $-60,6 \%$ \\
\hline Moxifloxacin & 235 & 88 & $-62,5 \%$ \\
\hline
\end{tabular}

Table 5: Initiation of antibiotics prescriptions in pediatrics in the period under study [2].

\begin{tabular}{|l|c|c|c|}
\hline Systemic antibiotics (pediatrics) & $\mathbf{2 0 1 9 / 2 0}$ & $\mathbf{2 0 2 0 / 2 1}$ & Variation \\
\hline Amoxicillin & 1.999 & 456 & $-77,2 \%$ \\
\hline Amoxicillin/ clavulanate & 714 & 431 & $-39,6 \%$ \\
\hline Azithromycin & 563 & 186 & $-67,0 \%$ \\
\hline Total antibiotics & 3.402 & 1.190 & $-65,0 \%$ \\
\hline
\end{tabular}

Table 6: New prescriptions of non-NSAID analgesics in the study period [2].

\begin{tabular}{|l|c|c|c|}
\hline N02B - Other analgesics and antipyretics & $\mathbf{2 0 1 9 / 2 0}$ & $\mathbf{2 0 2 0 / 2 1}$ & Variation \\
\hline Metamizole & 8.689 & 7.483 & $-13,9 \%$ \\
\hline Paracetamol alone & 15.388 & 10.983 & $-28,6 \%$ \\
\hline Paracetamol with codeine & 4.434 & 1.343 & $-69,7 \%$ \\
\hline
\end{tabular}


Valverde Bilbao E (2020) Analysis of the New Prescriptions Created in Our Organization during the First Twelve Months after the Declaration of the State of Alarm Due to SARS-CoV-2

In summary, the creation of new prescriptions in the last year compared to the previous year has been reduced by $25.9 \%$; however, the dispensing of drugs in pharmacy offices has only been reduced by $3 \%$. This means that the medication consumed by the Bidasoa IHO population has been quantitatively similar to that of the previous year, probably due to the successive automatic extensions of medications that have been applied during this time.

\section{References}

1. Mendizabal Olaizola A, Valverde Bilbao E (2020) Impacto de la pandemia SARSCoV-2 en el inicio de las prescripciones. J Healthc Qual Res 402-403.

2. Data obtained from Osakidetza's OAS (Oracle Analytics Server) tool.

3. Data obtained from Health Department's OBIEE (Oracle Business Intelligence Enterprise Edition) tool.

\section{Citation:}

Mendizabal Olaizola A, Valverde Bilbao E (2021) Analysis of the New Prescriptions Created in Our Organization during the First Twelve Months after the Declaration of the State of Alarm Due to SARS-CoV-2. J Int Pers COVID-19 Volume 1(1): 1-3. 